\title{
Response to Majeranowski
}

\author{
Claire Dossier $^{1}$ • Julien Hogan ${ }^{1}$ \\ Received: 1 February 2021 / Accepted: 2 February 2021 / Published online: 10 March 2021 \\ (C) IPNA 2021
}

Dear Editors,

We read with interest the comment from Dr. Majeranowski on our recently published article entitled "A global anti-B cell strategy combining obinutuzumab and daratumumab in severe pediatric nephrotic syndrome" and appreciate the discussion of the mechanisms of action of type II antiCD20 mAb.

The mechanisms of infusion-related reactions (IRR) after the infusion of anti-CD20 mAb are not fully understood, both in patients with $\mathrm{B}$ cell malignancies and immune-mediated diseases. In our retrospective report, we describe the occurrence of mild IRR during obinutuzumab infusion in 3/14 ( $21 \%$ ) patients, which is consistent with previous reports using other anti-CD20 mAb in childhood nephrotic syndrome. Indeed, Kamei et al. retrospectively reported 309 rituximab (RTX) infusions in 159 patients and found a high rate of IRR $(53 \%)$ but only $18 \%$ requiring a medical intervention. They also found a significant association between circulating $B$ cell count at the time of RTX infusion and IRR [1]. Bonanni et al. reported IRR in $6.7 \%$ of (RTX) infusions and $45 \%$ of ofatumumab infusions [2]. Despite the relatively high incidence of IRR, current protocols using RTX or ofatumumab are based on a single injection and do not recommend dividing the first dose [3].

As stated by Dr. Majeranowski in his letter, the recently published recommendation reviewed evidence from patients treated for chronic lymphocytic leukemia. Obinutuzumab is currently investigated in a wide range of autoimmune diseases and has been reported safe and effective in several small series. Moreover, a randomized controlled trial in lupus nephritis (NOBILITY, NCT02550652) that recently released its preliminary results as well as two other ongoing trials in lupus nephritis and membranous nephropathy (NCT04221477, NCT04702256, NCT 04629248) use two infusions of $1000 \mathrm{mg}$ of obinutuzumab at Days 0 and 15, repeated after 6 months, and do not recommend to divide the dose as done in the treatment of malignancies.

We agree that tolerance, including both infusion-related reactions and early and late adverse events, is an essential concern in our population. However, we believe that data and practices from chronic lymphocytic leukemia cannot be fully extrapolated in immune-mediated indications.

\section{References}

1. Kamei K, Ogura M, Sato M, Ito S, Ishikura K (2018) Infusion reactions associated with rituximab treatment for childhood-onset complicated nephrotic syndrome. Pediatr Nephrol 33:1013-1018

2. Bonanni A, Calatroni M, D'Alessandro M, Signa S, Bertelli E, Cioni M, Di Marco E, Biassoni R, Caridi G, Ingrasciotta G, Bertelli R, Di Donato A, Bruschi M, Canepa A, Piaggio G, Ravani P, Ghiggeri GM (2018) Adverse events linked with the use of chimeric and humanized anti-CD20 antibodies in children with idiopathic nephrotic syndrome. Br J Clin Pharmacol 84:1238-1249

3. Ravani P, Bonanni A, Ghiggeri GM (2017) Randomised controlled trial comparing ofatumumab to rituximab in children with steroiddependent and calcineurin inhibitor-dependent idiopathic nephrotic syndrome: study protocol. BMJ Open 7:e013319

Publisher's note Springer Nature remains neutral with regard to jurisdictional claims in published maps and institutional affiliations.

Claire Dossier

claire.dossier@aphp.fr

1 Pediatric Nephrology Department, Hopital Robert-Debré, APHP, Paris, France 